\title{
Cardiac Rehabilitation Exercise Training for High-Risk Cardiac Patients
}

\author{
Hee Eun Choi, $\mathrm{MD}^{1}$, Chul Kim, MD, $\mathrm{PhD}^{2}$, Yukyung Sohn, $\mathrm{MD}^{2}$ \\ ${ }^{1}$ Department of Rehabilitation Medicine, Inje University Haeundae Paik Hospital, Inje University College of Medicine, Busan;
${ }^{2}$ Department of Rehabilitation Medicine, Inje University Sanggye Paik Hospital, Inje University College of Medicine, Seoul, Korea
}

Objective To examine the effect and safety of cardiac rehabilitation (CR) program in high-risk cardiac patients and compare these results to those of control CR participants without high-risk criteria.

Methods A total of 12 high-risk cardiac patients were recruited as subjects. The high-risk criteria were: advanced heart failure with left ventricular ejection fraction (LVEF) of less than $30 \%$, a recent history of cardiac arrest or dangerous arrhythmia, and cardiac device insertion. Another 12 CR participants without any high-risk criteria mentioned above were recruited as controls. Both groups underwent 6 to 8 weeks of CR exercise training. Exercise tolerance tests were performed before and after completion of the CR program. After CR completion, both groups were evaluated and their results were compared.

Results After completion of the CR exercise program, both groups showed significant increases in peak oxygen uptake $\left(\mathrm{VO}_{2 \text { peak }}\right)$ and LVEF. In the control group ( $\left.\mathrm{n}=12\right), \mathrm{VO}_{2 \text { peak }}$ increased from 25.9 to $31.8 \mathrm{~mL} / \mathrm{kg} / \mathrm{min}$ (changing rate, $+21.4 \% \pm 22.1 \%$ ) and LVEF increased from $56.1 \%$ to $59.1 \%$ (changing rate, $+5.3 \% \pm 8.4 \%$ ). In the high-risk group ( $\mathrm{n}=12$ ), $\mathrm{VO}_{2 \text { peak }}$ increased from 16.8 to $21.0 \mathrm{~mL} / \mathrm{kg} / \mathrm{min}$ (changing rate, $+28.6 \% \pm 21.4 \%$ ) and LVEF increased from $26.1 \%$ to $29.4 \%$ (changing rate, $+16.1 \% \pm 12.9 \%$ ). There was no serious cardiovascular event during all exercise hours.

Conclusion High-risk cardiac patients who completed a supervised CR program demonstrated significant improvements in $\mathrm{VO}_{2 \text { peak }}$ and $\mathrm{LVEF}$ without any serious cardiovascular event. The improvement rate was similar to that of control group.

Keywords Heart failure, Defibrillators, Implantable, Exercise, Rehabilitation

\section{INTRODUCTION}

There is a growing consensus that exercise has a benefi- cial effect on patients with cardiovascular disease, even for those with severely impaired cardiac function because physical inactivity accelerates the severity of heart failure

Received August 11, 2016; Accepted October 14, 2016

Corresponding author: Yukyung Sohn

Department of Rehabilitation Medicine, Inje University Sanggye Paik Hospital, Inje University College of Medicine, 1342 Dongil-ro, Nowon-gu, Seoul 01757, Korea. Tel: +82-2-950-1134, Fax: +82-2-935-3076, E-mail: s3320@paik.ac.kr

ORCID: Hee Eun Choi (http://orcid.org/0000-0002-8753-929X); Chul Kim (http://orcid.org/0000-0001-8223-2945); Yukyung Sohn (http://orcid. org/0000-0002-1078-8415).

(c) This is an open-access article distributed under the terms of the Creative Commons Attribution Non-Commercial License (http://creativecommons.org/ licenses/by-nc/4.0) which permits unrestricted noncommercial use, distribution, and reproduction in any medium, provided the original work is properly cited. Copyright ( 2017 by Korean Academy of Rehabilitation Medicine 
(HF) [1]. Patients with chronic heart failure (CHF) have a reduced exercise tolerance as a result of several abnormalities in multiple organ systems. The reduced exercise tolerance further deteriorates exercise capacity, creating a vicious cycle of progressive deconditioning and worsening of HF [2]. In the last decade, several studies have demonstrated that HF patients in the New York Heart Association functional class II and III can benefit from moderate exercise training with significant improvements in exercise capacity, quality of life, and reduction in hospitalizations $[3,4]$.

Implantable cardioverter defibrillator (ICD) can improve the survival of patients with HF and significant left ventricular dysfunction $[5,6]$. Patients with ICDs frequently have fear over receiving shock during exercise. The fear of inappropriate shocks is a commonly cited cause when ICD patients are denied referral to an exercise training program [7]. However, due to the benefit of exercise, the ACC/AHA HF Guidelines has recommended exercise training [8]. More recently, the HF-ACTION (Heart Failure: A Controlled Trial Investigating Outcomes of Exercise Training) trial, a multicenter randomized controlled trial enrolling 2,331 medically stable outpatients with CHF, has demonstrated a smaller but significant improvement in peak oxygen uptake $\left(\mathrm{VO}_{2 \text { peak }}\right)$ at three months which has persisted to 12 months [9]. Many pioneers have applied exercise training in high-risk patients and documented the safety and beneficial effects of exercise training on those patients [9-11].

The aim of this study was to determine the effect and safety of cardiac rehabilitation (CR) program in high-risk patients, including advanced HF, history of life-threatening arrhythmias, and implanted ICD and/or cardiac resynchronization therapy (CRT). We compared and analyzed the results of CR program between high-risk and non-high-risk cardiac patients through reviewing medical records retrospectively.

\section{MATERIALS AND METHODS}

\section{Subjects}

We enrolled patients who visited a Cardiac Rehabilitation Clinic between January 2012 and December 2015. Their medical records were reviewed and analyzed retrospectively. Following the risk stratification published by the American Association of Cardiovascular and Pul- monary Rehabilitation (AACVPR) guidelines [12], CR participants with a high-risk for cardiovascular events during exercise training were included as study subjects. High-risk patients were defined as those with advanced HF (left ventricular ejection fraction $[\mathrm{LVEF}]<30 \%$ ), or a recent history of cardiac arrest or dangerous arrhythmia such as sustained ventricular tachycardia (VT) or ventricular fibrillation (VF), and early periods of cardiac device insertion including ICD or ICD with CRT. Patients who received PCI for an acute MI without any highrisk criteria mentioned above $(n=121)$ were included as control group. In order to minimize the selection bias, matched control groups were selected based on gender, age, and basic demographic data during the same period $(n=64)$. These control groups were randomized by an Excel program to match the number $(n=12)$ of the high-risk group. Twelve patients were enrolled for the high-risk group. The control group also included 12 patients. They all completed the exercise program. Pre-exercise reviews of clinical data including the results of a transthoracic echocardiogram (TTE) and/or a pacemaker summary were performed. Medications did not change during the 6 to 8 weeks study period. This study was performed according to the Declaration of Helsinki. It was approved by the Sanggye Paik Hospital Institutional Review Board (IRB No. 2016-02-008).

\section{Exercise testing}

All study subjects received an exercise tolerance test (ETT) and a baseline test. Follow-up tests were performed after completing 6 to 8 weeks of exercise training. An ETT was conducted to evaluate the cardiovascular response to exercise to ensure that the patient could tolerate the exercise in both groups. A symptom-limited ETT was conducted using a modified Bruce protocol. A real-time recording 12-channel electrocardiograph (ECG) (Q4500; Quinton Instrument Co., Boston, MA, USA); a respiratory gas analyzer (TrueOne 2400 Metabolic Measurement System; ParvoMedics, Inc., East Sandy, UT, USA); an automatic blood pressure (BP) and pulse monitor (Model 412, Quinton Instrument) and a treadmill (Medtrack ST 55, Quinton Instrument) were used for the ETT. The ETT measured a $\mathrm{VO}_{\text {2peak }}$, duration of exercise and submaximal myocardial oxygen demand $\left(\mathrm{MVO}_{2}\right)$. $\mathrm{VO}_{2 \text { peak }}$ was measured with a respiratory gas analyzer. Peak heart rate, resting heart rate, and $\mathrm{MVO}_{2}$ were estimated with the 
ECG and automatic BP and pulse monitor. The $\mathrm{MVO}_{2}$ was calculated by multiplying systolic $\mathrm{BP}$ and heart rate as a rate pressure product (RPP). Submaximal $\mathrm{MVO}_{2}$ was measured at the end of stage III of the modified Bruce protocol.

\section{Exercise training}

Both groups participated in an ambulatory supervised exercise training program for 6 to 8 weeks. One experienced physical therapist who specialized in CR supervised the training sessions. Three exercise sessions per week were offered. The duration of each session was approximately 60 minutes. Exercise intensity of $60 \%$ to $85 \%$ heart rate reserve (HRR) was individually calculated for each patient using the Karvonen formula ([maximal heart rate-resting heart rate×\%intensity]+resting heart rate). The target heart rate was calculated at $60 \%$ of the HRR during the first 2 weeks, at $70 \%$ of HRR during the third and fourth weeks, and at $85 \%$ of HRR during the remained periods. ICD patients were instructed not to surpass an upper heart rate threshold. This threshold was set at the detection rate of ICD minus 30 beats/min. During the training sessions, individual BP, ECG, and heart rate were strictly monitored. The exercise stop criteria included in the American Heart Association guidelines were strictly followed during exercises [12].

\section{Statistical analysis}

Data analyses were performed using SPSS ver. 18.0 (SPSS Inc., Chicago, IL, USA). Data is reported as a mean \pm standard deviation unless otherwise stated. When comparing two groups, paired t-tests or Mann-Whitney

Table 1. Demographic data of both groups

\begin{tabular}{|lccc}
\hline & High-risk group (n=12) & Non-high-risk group (n=12) & p-value \\
\hline Gender (male:female) & $9: 3$ & $10: 2$ & 0.615 \\
\hline Age $(\mathrm{yr})$ & $59.4 \pm 14.1$ & $62.0 \pm 10.9$ & 0.622 \\
\hline Hypertension & $4(33.3)$ & $4(33.3)$ & 1 \\
\hline Diabetes & $3(25.0)$ & $6(50)$ & 0.206 \\
\hline $\mathrm{LVEF}$ & $26.1 \pm 10.9$ & $56.1 \pm 6.4$ & $0.001^{* *}$ \\
$\mathrm{VO}_{\text {peak }}(\mathrm{mL} / \mathrm{kg} / \mathrm{min})$ & $16.8 \pm 4.7$ & $24.3 \pm 7.1$ & $0.006^{* *}$ \\
\hline $\mathrm{hsCRP}(\mathrm{mg} / \mathrm{dL})$ & $2.6 \pm 5.7$ & $1.3 \pm 3.4$ & 0.524 \\
\hline $\mathrm{HbAlc}(\%)$ & $6.1 \pm 0.8$ & $5.8 \pm 0.5$ & 0.272 \\
\hline History of smoking & & & 0.443 \\
\hline Never & $7(58.3)$ & $4(33.3)$ & 0.234 \\
\hline Current smoker & $3(25.0)$ & $4(33.3)$ & 0.296 \\
\hline Ex-smoker & $2(16.7)$ & $4(33.3)$ & \\
Current medications & & & 0.615 \\
ACEi & $2(16.7)$ & $3(25.0)$ & 0.346 \\
\hline ARB & $4(33.3)$ & $2(16.7)$ & 1 \\
\hline$\alpha, \beta$-Blocker & $4(33.3)$ & $4(33.3)$ & $0.009^{* *}$ \\
\hline$\beta$-Blocker & $1(8.3)$ & $7(58.3)$ & 0.307 \\
\hline CCB & $0(0.0)$ & $1(8.3)$ & $0.012^{*}$ \\
\hline Statins & $7(58.3)$ & $12(100)$ & 0.219 \\
\hline Nitrates & $5(41.7)$ & $8(66.7)$ & $0.012^{*}$ \\
\hline Aspirin & $7(58.3)$ & $12(100)$ & 0.333 \\
\hline Clopidogrel & $11(93.8)$ & $12(100)$ & \\
\hline
\end{tabular}

Values are presented as mean \pm standard deviation or number (\%).

LVEF, left ventricular ejection fraction; $\mathrm{VO}_{2 \text { peak }}$, peak oxygen consumption; hsCRP, high-sensitivity $\mathrm{C}$ reactive protein; $\mathrm{HbAlc}$, hemoglobin Alc; ACEi, angiotensin converting enzyme inhibitor; ARB, angiotensin receptor blocker; CCB, calcium channel blocker.

${ }^{*} \mathrm{p}<0.05,{ }^{* *} \mathrm{p}<0.01$. 
U-tests were used depending on the normality of distribution. To compare gender, smoking status, and drug history, Pearson chi-square tests and Fisher exact tests were used. To compare the effects of exercise between the two groups, a Wilcoxon signed-rank test was used. A repeated two-way analysis of variance (ANOVA) was used to test between-group differences in the changes of outcome variables from before to after exercise training. All tests were two-tailed and a p-value of less than 0.05 was considered as statistically significant.

\section{RESULTS}

\section{Patient characteristics}

Characteristics of the 12 patients with the high-risk group and the 12 control patients are summarized in Table 1. The high-risk group consisted of 9 males and 3 females, while the control group consisted of 10 males and 2 females. There was no significant difference in the distribution of gender, age, diabetes, or smoking status between the two groups. However, drugs, beta blockers, statins, and aspirin were generally taken more by the control group. This is due to the fact that most patients in the control group have acute coronary syndrome. According to the baseline laboratory parameters, LVEF and $\mathrm{VO}_{2 \text { peak }}$ in the high-risk group were significantly lower than those in the control group.
The high-risk group included 11 advanced HF patients $(<20 \%$ in 6 cases) and one sudden cardiac death syndrome. Five of them received ICD including one CRT (Table 2). The LVEF of HF patients was all under 30 percent. The most common reason for inserting an ICD or ICD with CRT was ventricular fibrillation.

\section{Data comparison before and after the cardiac rehabilitation program}

All patients completed the six to eight weeks of cardiac rehabilitation training program. After exercise training, the $\mathrm{VO}_{2 \text { peak }}$ was increased from an average of 16.8 to 21.0 $\mathrm{mL} / \mathrm{kg} / \mathrm{min}$ in the high-risk group and from 24.3 to 30.0 $\mathrm{mL} / \mathrm{kg} / \mathrm{min}$ in the non-high-risk group (Table 3). Such an increase was statistically significant $(\mathrm{p}<0.05)$ in both groups. The rate of change in $\mathrm{VO}_{2 \text { peak }}$ was $28.6 \%$ in the high-risk group, which was higher than $21.5 \%$ in the nonhigh-risk group (Table 4). However, such a difference was not statistically significant $(p>0.05)$. Exercise tolerance duration was significantly increased in the high-risk group. Individual values of $\mathrm{VO}_{2 \text { peak }}$ before and after the training in each group are shown in Fig. 1.

After 6 to 8 weeks of CR exercise training, the LVEF was increased from the average of $26.1 \%$ to $29.4 \%$ in the highrisk group and from $56.1 \%$ to $59.1 \%$ in the non-high-risk group (Table 5). The increase was statistically significant $(p<0.05)$ in both groups. The rate of change in LVEF was

Table 2. Clinical data of high-risk group

\begin{tabular}{ccllcclc}
\hline No. & Age (yr) & Sex & Diagnosis & Duration (day) & LVEF (\%) & Dysrhythmia & Device \\
\hline 1 & 42 & Male & DCMP & 57 & 18 & VF & ICD \\
\hline 2 & 56 & Male & DCMP & 75 & 28 & VF, frequent SVT & ICD \\
\hline 3 & 54 & Male & DCMP & 30 & 14 & VF & ICD \\
4 & 65 & Male & SCD & 78 & 45 & VF, AF & ICD \\
\hline 5 & 54 & Female & DCMP & 36 & 11 & AF, SVT & CRT+ICD \\
\hline 6 & 41 & Male & DCMP & 16 & 20 & AF & - \\
\hline 7 & 85 & Female & STEMI & 15 & 30 & VT during CAG & - \\
\hline 8 & 66 & Male & CABG & 54 & 24 & Incomplete LBBB & - \\
\hline 9 & 61 & Male & CABG & 32 & 25 & No & - \\
\hline 10 & 43 & Male & CABG & 16 & 21 & No & - \\
\hline 11 & 67 & Male & CABG & 50 & 25 & No & - \\
\hline 12 & 80 & Female & STEMI & 5 & 20 & No & - \\
\hline
\end{tabular}

DCMP, dilated cardiomyopathy; SCD, sudden cardiac death; STEMI, ST elevation myocardial infarction; CABG, coronary artery bypass graft; LVEF, left ventricular ejection fraction; VF, ventricular fibrillation; SVT, supraventricular tachycardia; AF, atrial fibrillation; VT, ventricular tachycardia; CAG, coronary angiography; LBBB, left bundle branch block; ICD, implanted cardioverter defibrillator; CRT, cardiac resynchronization therapy. 


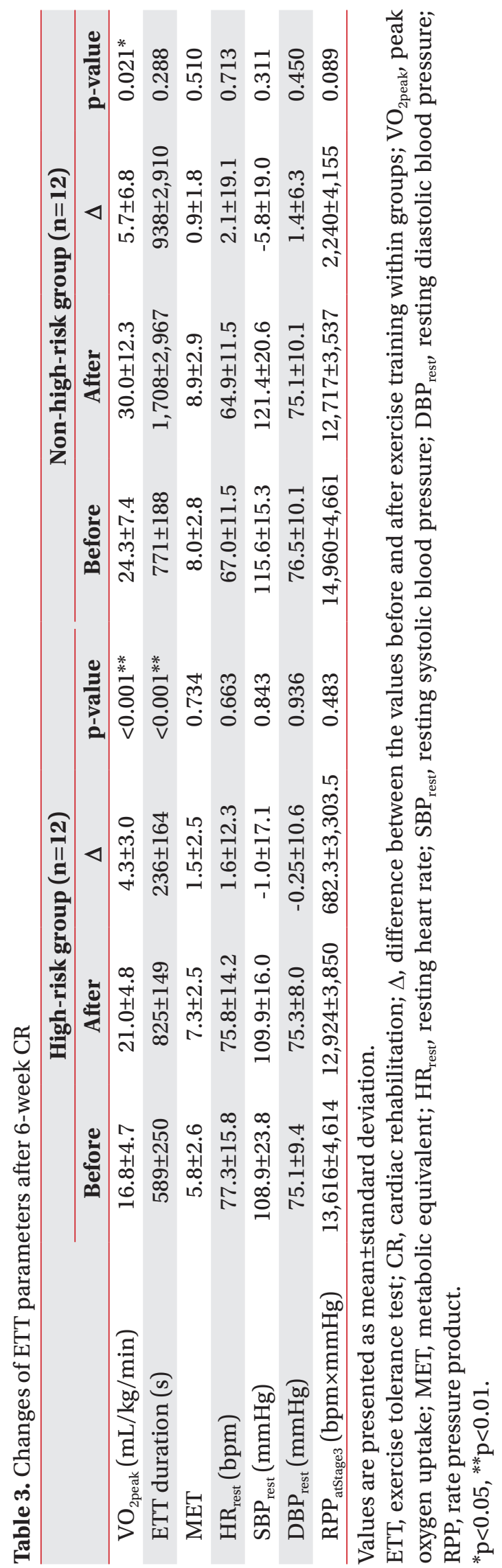

Table 4. Comparison of change rate between the two groups before and after CR

\begin{tabular}{lccc}
\hline & $\begin{array}{c}\text { High-risk } \\
\text { group }\end{array}$ & $\begin{array}{c}\text { Non-high-risk } \\
\text { group }\end{array}$ & p-value \\
\hline $\mathrm{VO}_{\text {2peak }}(\%)$ & $28.59 \pm 21.43$ & $21.48 \pm 22.14$ & 0.551 \\
$\operatorname{LVEF}(\%)$ & $16.12 \pm 12.92$ & $5.29 \pm 8.36$ & 0.107 \\
\hline
\end{tabular}

Values are presented as mean \pm standard deviation.

$\mathrm{CR}$, cardiac rehabilitation; $\mathrm{VO}_{\text {2peak }}$, peak oxygen uptake; LVEF, left ventricular ejection fraction.

Changing rate $=(\mathrm{B}-\mathrm{A}) / \mathrm{A} \times 100 ; \mathrm{A}$, baseline before $\mathrm{CR} ; \mathrm{B}$, result after $\mathrm{CR}$.

${ }^{*} \mathrm{p}<0.05,{ }^{* *} \mathrm{p}<0.01$.

$16.1 \%$ in the high-risk group, which was higher than $5.3 \%$ in the non-high-risk group (Table 4). However, such a difference was not statistically significant $(p>0.05)$. Stroke volume significantly $(\mathrm{p}<0.05)$ increased in the high-risk group. The individual values of LVEF before and after the training in each group are shown in Fig. 2.

\section{Cardiovascular-related complications during exercise monitoring}

During the intervention period, there was no adverse cardiovascular event and symptomatic arrhythmias. Fatal cardiac complications such as cardiac arrest, death, and myocardial infarction were not observed. No inappropriate discharge was delivered by the ICDs at any time during exercise testing or training. No patient experienced any complication that required immediate medical attention during the exercise testing or training. All the 24 subjects finished the CR program.

\section{DISCUSSION}

The AACVPR guideline 2004 published risk stratification for cardiovascular complications that can develop with exercise [13]. According to this stratification, the high-risk group was defined as patients with advanced HF (LVEF $<30 \%$ ), a recent history of cardiac arrest or dangerous arrhythmia such as sustained VT or VF, and early periods of cardiac device insertion including ICD or ICD with CRT.

In the present study, exercise capacities before and after training were compared between high-risk group of patients $(\mathrm{n}=12)$ and a control group of cardiac patients $(\mathrm{n}=12)$. The exercise program was feasible. It was performed by the 12 high-risk patients for 6 to 8 weeks with- 

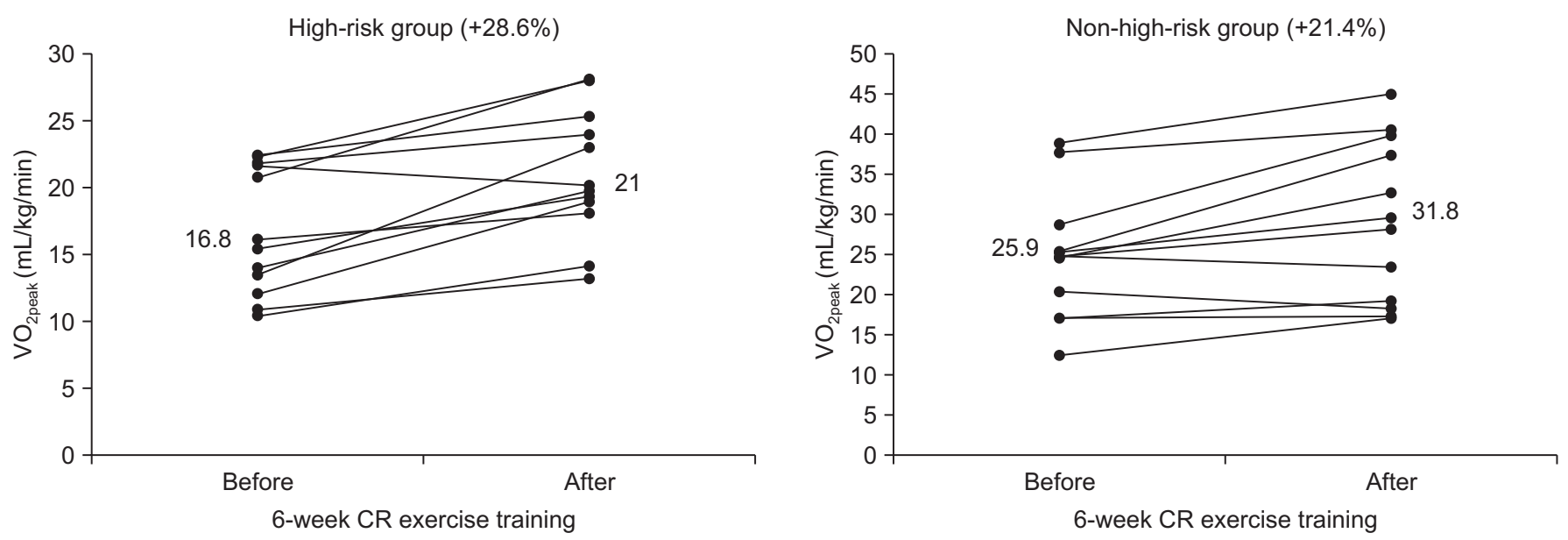

Fig. 1. The individual values for peak oxygen uptake $\left(\mathrm{VO}_{2 \text { peak }}\right)$ before and after training in each group.

Table 5. Changes of cardiac echogenic parameters after 6-week CR

\begin{tabular}{|c|c|c|c|c|c|c|c|c|}
\hline & \multicolumn{4}{|c|}{ High-risk group $(n=12)$} & \multicolumn{4}{|c|}{ Non-high-risk group $(n=12)$} \\
\hline & Before & After & $\Delta$ & p-value & Before & After & $\Delta$ & p-value \\
\hline LVEF (\%) & $26.1 \pm 10.9$ & $29.4 \pm 10.1$ & $3.3 \pm 2.6$ & $0.001^{* *}$ & $56.1 \pm 6.4$ & $59.1 \pm 8.2$ & $3.0 \pm 4.5$ & $0.042^{*}$ \\
\hline $\mathrm{SV}(\mathrm{mL})$ & $57.2 \pm 14.4$ & $66.9 \pm 15.1$ & $9.7 \pm 10.3$ & $0.01^{*}$ & $68.1 \pm 11.1$ & $74.4 \pm 12.7$ & $6.3 \pm 13.8$ & 0.142 \\
\hline LVESD (cm) & $5.6 \pm 1.2$ & $5.4 \pm 1.0$ & $-0.1 \pm 0.5$ & 0.410 & $3.4 \pm 0.5$ & $3.4 \pm 0.3$ & $-0.008 \pm 0.1$ & 0.940 \\
\hline $\operatorname{LVEDD}(\mathrm{cm})$ & $6.5 \pm 1.0$ & $6.4 \pm 0.9$ & $-0.02 \pm 0.5$ & 0.904 & $5.1 \pm 0.4$ & $5.0 \pm 0.3$ & $-0.1 \pm 0.4$ & 0.383 \\
\hline
\end{tabular}

Values are presented as mean \pm standard deviation.

$\mathrm{CR}$, cardiac rehabilitation; $\Delta$, difference between the values before and after exercise training within groups; LVEF, left ventricular ejection fraction; SV, stroke volume; LVESD, left ventricular end systolic diameter; LVEDD, left ventricular end diastolic diameter.

${ }^{*} \mathrm{p}<0.05,{ }^{* *} \mathrm{p}<0.01$.
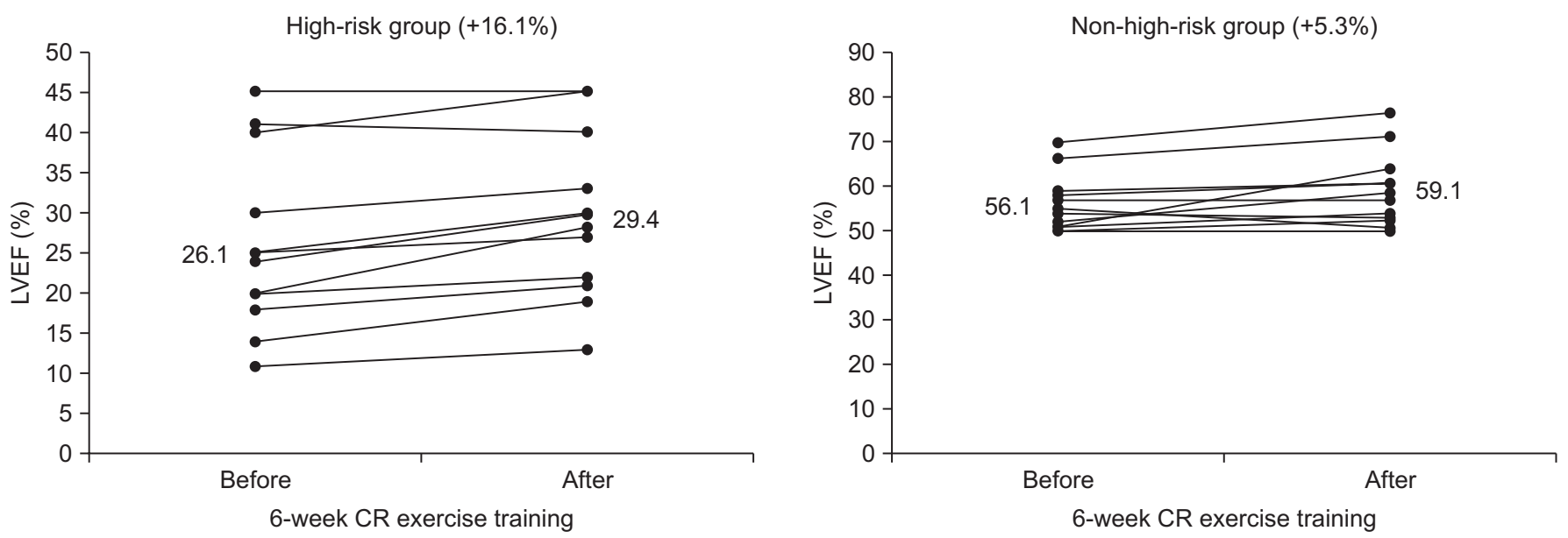

Fig. 2. The individual values for left ventricular ejection fraction (LVEF) before and after training in each group.

out any arrhythmic event. In previous studies, exercise testing of patients with a history of malignant arrhythmias has shown high rates of arrhythmic complications
[14]. It has been reported that the risk of cardiovascular complications during exercise testing and exercise training is higher in patients with a history of threatening ar- 
rhythmias or cardiac arrest $[14,15]$. A few studies have reported the safety and feasibility of physical activity and exercise-related complications in patients with malignant ventricular arrhythmias $[14,16]$. In our study, no serious cardiovascular complication such as cardiac arrest and any arrhythmia with hemodynamic compromise was observed, suggesting that careful monitoring during exercise training and prescription of a suitable exercise program can effectively decrease the risk and fear of exercise-related complications. Therefore, CR could be actively applied to high-risk patients.

Several cases have also described inappropriate ICD discharges in patients during exercise $[17,18]$. The fear of inappropriate shocks is a commonly cited reason when ICD patients are denied referral to an exercise training program [7]. A recent study has revealed that the risk for ICD shock related to a traditional exercise training program is low as most of these patients have been revascularized after undergoing stress testing prior to exercise training [19]. Piccini et al. [20] have performed a controlled trial of exercise training. The trial included a total of 2,331 randomized patients with HF and an ejection fraction of $\leq 35 \%$ to exercise training or usual care. A total of $108(20 \%)$ of the exercise patients had shock while $113(22 \%)$ of the control patients had shock. There was no evidence of increased ICD shocks or reduced left ventricular function for those who underwent exercise training, indicating that exercise therapy for ICD recipients with HF should not be prohibited.

In our study, no inappropriate discharge was delivered by the ICDs at any time during exercise testing or training. Furthermore, no patient experienced any complication that required immediate medical attention during exercise testing or during training. The initial device adjustments to ensure a safety threshold (from inducible HR to ICD shock threshold) might have reduced the risk of inappropriate shocks during exercise.

Aerobic exercise capacity measured as $\mathrm{VO}_{2 \text { peak }}$ has been shown to be the strongest predictor of both all-cause mortality and cardiac mortality among patients with cardiovascular disease $[1,21]$. This study revealed that the values of $\mathrm{VO}_{2 \text { peak }}$ and LVEF were significantly increased in both groups after cardiac rehabilitation, suggesting that exercise capacity could be increased after exercise training and a CR program, even in high-risk patients. Particularly, the high increase of $\mathrm{VO}_{2 \text { peak }}$, which is closely related to survival rates might bring great benefit to highrisk patients. The change rate of $\mathrm{VO}_{2 \text { peak }}$ was $28.6 \%$ in the high-risk group which was much higher than that $21.4 \%$ in the non-high-risk group, although the difference was not statistically significant. The higher change rate of $\mathrm{VO}_{\text {2peak }}$ in the high-risk group might be due to the lower initial $\mathrm{VO}_{\text {2peak }}$ in the high-risk group compared to that in the non high-risk group. This result is consistent with results of previous studies showing a higher increase in the rate of in $\mathrm{VO}_{2 \text { peak }}$ after a cardiac rehabilitation program with a lower initial $\mathrm{VO}_{\text {2peak }}[22]$.

It has been shown that regular exercise training can lead to a modest but significant decline in cardiac size and an improvement in left ventricular function in patients with moderate CHF [23]. However, our study revealed that exercise training was more effective in patients with advanced HF compared to control cardiac patients. The LVEF was improved. However, there was no significant change in left ventricular end-diastolic volume (LVEDV). These results suggested that LVEF might have been improved by the enhancement of intestinal/splenic venoconstriction, in agreement with the result of a previous study showing improved autonomic function after exercise training [24]. It has been previously shown that exercise training can lead to partial correction of peripheral endothelial dysfunction in patients with moderate $\mathrm{CHF}$ [25]. Given that the vascular tone of peripheral arteries is one component of afterload, it is obvious that the improvement in endothelial function observed after aerobic endurance exercise training is inversely correlated with the decline in systemic vascular resistance as shown in a previous study [23]. Therefore, the improvement in left ventricular function is at least partially the result of an exercise training-induced decline in afterload.

This study had the following limitations. First, our study was conducted retrospectively using medical records of subject patients. For this reason, a selection bias cannot be ruled out. Second, the number of subjects was quite small which limited the study's validity on safety. Third, this study did not have a longer follow-up after 8 weeks. Therefore, the long-term improvement in exercise capacity after the exercise program could not be confirmed. Despite these limitations, this study safely implemented CR in patients with high-risk for cardiac events and found obvious improvement in exercise capacity.

In conclusion, high-risk cardiac patients who complet- 
ed a 6- to 8-week supervised CR program demonstrated significant improvement in $\mathrm{VO}_{\text {2peak }}$ and LVEF without any serious cardiovascular event or negative remodeling of left ventricular wall. There was no statistically significant difference in the rate of improvement between the highrisk cardiac group and the control group without highrisk. The present study suggests that exercise training in high-risk patients is feasible and safe. It can provide a cumulative benefit in terms of exercise capacity. Therefore, exercise training for high-risk patients can be encouraged in clinical applications. More study is needed to further elaborate the role of CR in this patient cohort with a larger number of patients.

\section{CONFLICT OF INTEREST}

No potential conflict of interest relevant to this article was reported.

\section{REFERENCES}

1. Kavanagh T, Mertens DJ, Hamm LF, Beyene J, Kennedy J, Corey P, et al. Prediction of long-term prognosis in 12169 men referred for cardiac rehabilitation. Circulation 2002;106:666-71.

2. Belardinelli R, Capestro F, Misiani A, Scipione P, Georgiou D. Moderate exercise training improves functional capacity, quality of life, and endotheliumdependent vasodilation in chronic heart failure patients with implantable cardioverter defibrillators and cardiac resynchronization therapy. Eur J Cardiovasc Prev Rehabil 2006;13:818-25.

3. Wilson JR, Groves J, Rayos G. Circulatory status and response to cardiac rehabilitation in patients with heart failure. Circulation 1996;94:1567-72.

4. Belardinelli R, Georgiou D, Cianci G, Purcaro A. Randomized, controlled trial of long-term moderate exercise training in chronic heart failure: effects on functional capacity, quality of life, and clinical outcome. Circulation 1999;99:1173-82.

5. Bardy GH, Lee KL, Mark DB, Poole JE, Packer DL, Boineau R, et al. Amiodarone or an implantable cardioverter-defibrillator for congestive heart failure. $\mathrm{N}$ Engl J Med 2005;352:225-37.

6. Moss AJ, Zareba W, Hall WJ, Klein H, Wilber DJ, Cannom DS, et al. Prophylactic implantation of a defi- brillator in patients with myocardial infarction and reduced ejection fraction. N Engl J Med 2002;346:87783.

7. van Ittersum M, de Greef M, van Gelder I, Coster J, Brugemann J, van der Schans C. Fear of exercise and health-related quality of life in patients with an implantable cardioverter defibrillator. Int J Rehabil Res 2003;26:117-22.

8. Hunt SA, Abraham WT, Chin MH, Feldman AM, Francis GS, Ganiats TG, et al. ACC/AHA 2005 Guideline Update for the Diagnosis and Management of Chronic Heart Failure in the Adult: a report of the American College of Cardiology/American Heart Association Task Force on Practice Guidelines (Writing Committee to Update the 2001 Guidelines for the Evaluation and Management of Heart Failure): developed in collaboration with the American College of Chest Physicians and the International Society for Heart and Lung Transplantation: endorsed by the Heart Rhythm Society. Circulation 2005;112:e154-235.

9. Belardinelli R, Georgiou D, Cianci G, Purcaro A. 10year exercise training in chronic heart failure: a randomized controlled trial. J Am Coll Cardiol 2012;60: 1521-8.

10. O'Connor CM, Whellan DJ, Lee KL, Keteyian SJ, Cooper LS, Ellis SJ, et al. Efficacy and safety of exercise training in patients with chronic heart failure: HFACTION randomized controlled trial. JAMA 2009;301: 1439-50.

11. Isaksen K, Munk PS, Valborgland T, Larsen AI. Aerobic interval training in patients with heart failure and an implantable cardioverter defibrillator: a controlled study evaluating feasibility and effect. Eur J Prev Cardiol 2015;22:296-303.

12. Gibbons RJ, Balady GJ, Bricker JT, Chaitman BR, Fletcher GF, Froelicher VF, et al. ACC/AHA 2002 guideline update for exercise testing: summary article: a report of the American College of Cardiology/ American Heart Association Task Force on Practice Guidelines (Committee to Update the 1997 Exercise Testing Guidelines). Circulation 2002;106:1883-92.

13. American Association of Cardiovascular and Pulmonary Rehabilitation. Guidelines for cardiac rehabilitation and secondary prevention programs. 4 th ed. Champaign: Human kinetics; 2004. p. 53-84.

14. Young DZ, Lampert S, Graboys TB, Lown B. Safety of 
maximal exercise testing in patients at high risk for ventricular arrhythmia. Circulation 1984;70:184-91.

15. Pashkow FJ, Schweikert RA, Wilkoff BL. Exercise testing and training in patients with malignant arrhythmias. Exerc Sport Sci Rev 1997;25:235-69.

16. Allen BJ, Casey TP, Brodsky MA, Luckett CR, Henry WL. Exercise testing in patients with life-threatening ventricular tachyarrhythmias: results and correlation with clinical and arrhythmia factors. Am Heart J 1988; 116:997-1002.

17. Kou WH, Kirsh MM, Stirling MC, Kadish AH, Orringer CE, Morady F. Provocation of ventricular tachycardia by an automatic implantable cardioverter defibrillator. Am Heart J 1990;120:208-10.

18. Cohen TJ, Chien WW, Lurie KG, Lee MA, Lesh MD, Scheinman MM, et al. Implantable cardioverter defibrillator proarrhythmia: case report and review of the literature. Pacing Clin Electrophysiol 1991;14:1326-9.

19. Isaksen K, Morken IM, Munk PS, Larsen AI. Exercise training and cardiac rehabilitation in patients with implantable cardioverter defibrillators: a review of current literature focusing on safety, effects of exercise training, and the psychological impact of programme participation. Eur J Prev Cardiol 2012;19:804-12.

20. Piccini JP, Hellkamp AS, Whellan DJ, Ellis SJ, Keteyian SJ, Kraus WE, et al. Exercise training and implantable cardioverter-defibrillator shocks in patients with heart failure: results from HF-ACTION (Heart Failure and A Controlled Trial Investigating Outcomes of Exercise TraiNing). JACC Heart Fail 2013;1:142-8.

21. Myers J, Prakash M, Froelicher V, Do D, Partington S, Atwood JE. Exercise capacity and mortality among men referred for exercise testing. N Engl J Med 2002; 346:793-801.

22. Vanhees L, Stevens A, Schepers D, Defoor J, Rademakers F, Fagard R. Determinants of the effects of physical training and of the complications requiring resuscitation during exercise in patients with cardiovascular disease. Eur J Cardiovasc Prev Rehabil 2004;11:304-12.

23. Hambrecht R, Gielen S, Linke A, Fiehn E, Yu J, Walther $\mathrm{C}$, et al. Effects of exercise training on left ventricular function and peripheral resistance in patients with chronic heart failure: a randomized trial. JAMA 2000; 283:3095-101.

24. Holloway CJ, Dass S, Suttie JJ, Rider OJ, Cox P, Cochlin LE, et al. Exercise training in dilated cardiomyopathy improves rest and stress cardiac function without changes in cardiac high energy phosphate metabolism. Heart 2012;98:1083-90.

25. Hambrecht R, Fiehn E, Weigl C, Gielen S, Hamann C, Kaiser R, et al. Regular physical exercise corrects endothelial dysfunction and improves exercise capacity in patients with chronic heart failure. Circulation 1998;98:2709-15. 